\title{
Combining product and packaging design for increased added value and customer satisfaction
}

\begin{abstract}
Current paper shows an analysis of the conceptual design of products and packages that correspond to requested customer needs. A number of research tools, marketing/branding principles and product development techniques are presented. This study is an analytical demonstration of the whole design process from the concept to the final $3 D$ rendered models with the use of a number of tools and methodologies i.e. mind maps, mood boards, sketches. In other words, it is a combination of marketing and designing principles that transformed the raw data received from customers into 3D CAD (Computer Aided Design) modeled products; a set of sportive sunglasses paired with a hand-watch from the same product family and a set of classic sunglasses with a casual hand watch. Finally, this project can be considered a blend between theoretical and practical methods that have been chosen and practiced after extensive research.
\end{abstract}

\section{KEY WORDS}

product design, product development, packaging, branding

\author{
Theoklitos Vasileiadis ${ }^{1}$ \\ Anastasios Tzotzis ${ }^{2}$ (1) \\ Dimitrios Tzetzis ${ }^{1}$ \\ Panagiotis Kyratsis ${ }^{3}$ (D) \\ ${ }^{1}$ International Hellenic University, \\ School of Science and Technology, \\ Thermi, Greece \\ ${ }^{2}$ University of Zaragoza, \\ Department of Design and \\ Manufacturing Engineering, \\ Zaragoza, Spain \\ ${ }^{3}$ University of Western Macedonia, \\ Department of Industrial Design \\ Engineering, Kila Kozani, Greece
}

\author{
Corresponding author: \\ Panagiotis Kyratsis \\ e-mail:pkyratsis@uowm.gr
}

\section{Introduction}

Design is everywhere. Especially product design lies at the convergence of many human activities. From an economic aspect, a product is something that is sold from a company to its customers. The development of a new product begins with the identification of a market opportunity and ends in the production and its delivery to the customers; a novel approach on designing creative products and packages was presented in the work of Kyratsis et al. (2013) and Kyratsis et al. (2014) with the Design for Skin \& Shape methodology that creates a clear optical identity to the customer's mind for the product which is directly associated with the design. In addition, the proposed methodology can reduce the product development time since the concept is defined from the beginning of the design cycle. The packaging and branding have to connect to the product and of course to the expectations of the target market. The goal of this paper is to present step by step the whole design process of a new product and its packaging from the ideation stage to the final rendered CAD model based on a workflow similar to the one found in the studies of Kyratsis et al. (2015) and Alexandridis et al. (2016) where specialized computational tools and methodologies are combined having as an objective the optimization of a design considering its environmental impact.

Finally, this paper aims to present products that will satisfy actual customers' needs through innovative and 
aesthetically pleasing design. This means, that these products should have special features that are not currently used in the market or at least they are not so common. In order to do so, an extensive market research has been conducted to define the final product features.

\section{Literature Review}

Regarding the product development, the work of Urlich \& Eppinger (2012) provide knowledge and mechanisms related to Product Design and Marketing. They describe the whole new product development process starting from defining the design problem and gathering raw data from customers. On top of that, they analyze techniques of concept generation and selection in order to reach the stage of testing and manufacturing. According to the authors, an important aspect of the product design is the underlying reasons of bad design.

Norman (2013) presented ergonomic solutions to design problems and functions based on cognitive psychology, in order to design with respect to the user. Based on Norman (2013) it is not technology that makes things complicated during the conceptual design phase of a product, but the bad design itself. Manavis et al. (2019) proposed in their work nature-based design ideas that can lead to further opportunities for research and marketing success of the retail industry.

DuPuis \& Silva (2008) with their study on packaging design provide the reader with tools for choosing the best colors and materials in order to design a functional and aesthetically pleasing package to promote products in the marketplace. In addition, many examples on eco-friendly packaging and on innovative ways that materials can be used in design packages are available in the work of Sherr \& Dent (2015). Moutaftsi \& Kyratsis (2016) explored the benefits of a customer based approach on food packaging design by presenting a case study of a small production honey brand. Kouveli, Tzetzis \& Kyratsis (2017) in their research on the packaging design process from the company's perspective, state that packaging design is one of the most significant subunits of the product design field and emphasized on the fact that the package is the outer skin of the product, its protection layer and the first element on the consumer's vision.

Ambrose \& Harris (2011) explored methods by visually communicating the value of a product to its target audience and examined the entire lifespan of a piece of packaging: from its manufacture and construction, to its display in various retail environments, to its eventual disposal as well and finally to the associated environmental concerns. Wang (2013) studied the importance of visual packaging design and developed a theoretical model to show the effects of consumer attitudes toward visual food packaging on perceived product quality, product value, and brand preference. Crilly, Moultrie \& Clarkson (2004) conducted a research on how consumer respond to product visual form within the context of an integrated conceptual framework and emphasized on the aesthetic, semantic and symbolic aspects of cognitive response to design. Additionally, authors examined the role of external visual references and the effects of moderating influences at each stage in the process of communication.

Solomon (2017) investigated the consumer's aspect and psychology behind every decision regarding the purchases; his study presents how the consumers take decisions regarding the purchases and advertisement influence, the human sensory channels and consequently behavior. Last but not least, Bruce \& Daly (2007) studied the design management processes and activities from a marketing perspective primarily through the use of detailed cases.

Present paper aims to deliver a complete study on the product and packaging design, based on a combination of the most appropriate methodologies and strategies that were mentioned earlier, with ultimate goal to increase the value of the final products and thus fully satisfy the customer.

The production of an ecological product is more complex than it seems (Wever et al., 2010). The producer has to carefully analyze all the stages of the life cycle of the product in order to prevent the environmental damage, from production to disposal. One well known phrase to the world of design is 'less is more', which it is also significant in the case of the environmental impact. An extensive research of the materials can lead to a choice less harmful to the environment but also could result to the reduction of the required amount of material to produce the product. This means less time of processing and transportation, which could lead to economic growth due to the reduced costs.

As for the branding, the language has to be direct and clear (Ghodeswar, 2008). This is happening because customers most of the times dedicate only a few seconds on shelves in order to choose a product. Furthermore, the brand name could originate from words without meaning, but have pleasing and memorable syllables that suit with the products namesake. Sometimes companies name their products after intended misspellings of words, in order to create an intelligent and memorable word play. An early research on brand name characteristics and the associated strategies was conducted by Robertson (1989). The authors concluded that brand names should be simple, distinctive, meaningful, emotional, make use of morphemes, phonemes, alliteration, consonance, and should make a sound associate of product class, as well as being legally protectable; a wellplanned brand name will require less marketing money to achieve recall and image targets. Also, it is a common fact that companies take their product names after real 
or imaginary names that will work as a signature for the product. Colors also play a significant role to branding. This means that different colors correspond to accordingly different product attributes. For this reason, it is very useful for designers to pick a color palette when they are designing a packaging, in order to have better results in advertising the product (Kohli, 1997; Mohebbi, 2014).

\section{Research Design and Methodology}

Figure 1 illustrates the framework of the processes followed, so that the final concept design could be modeled based on the customers' needs. After the problem recognition, a number of interviews were conducted with customers, in order to collect the appropriate data regarding their needs. The gathered raw data were hierarchized with the analysis of an online questionnaire. Furthermore, mind maps, mood boards and conceptual sketches were implemented for the creation of new ideas. Finally an interview with experts was added to the already gathered data in order to select the final concept and generate the final 3D CAD models.

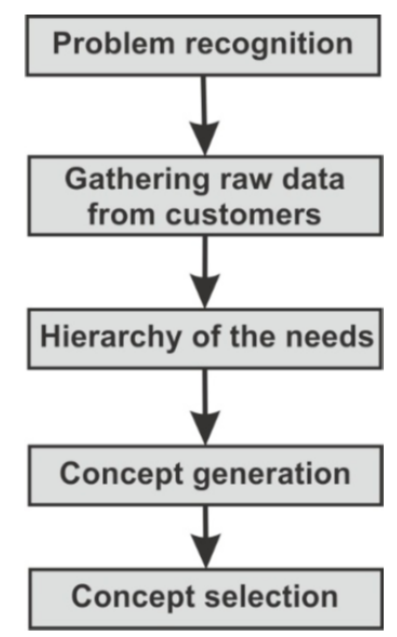

» Figure 1: Workflow Chart

\section{Product Opportunity Identification}

In a modern society, "smart" products provide many advantages, but also complexity. To be more specific, after the customer evaluates the hundreds of product choices and eventually chooses one, they have to deal with hundreds of complicated features, and mind-blowing tutorials and manuals. Experts call this feature creep. The aim of this study is to replace this complexity with the good design.

The sunglasses and hand watch were chosen as test products for this case study since they can eas- ily be combined; they are accessories that define the customer's style and way of living. In addition, their high functionality leads a number of people to carry them all the time. Another reason they have been selected, is because their development at a conceptual level is better understood by the customers. Their penetration in the people's life is high and their use is easily grasped by most of their users.

\section{Data Gathering}

Gathering data from customers was implemented by interviewing 10 customers and observing how they use these products during their daily routine. The participants of those interviews were both males and females. Eight of them were within the age group of 20 to 30 years old and two out of ten above 40 . According to van Kleef, van Trijp \& Luning (2005) 'it is generally assumed that when consumers respond to questions, their answers represent the true meaning'. For this reason, first the interviews were used in order to provide a solid basis for the number of features and issues that the customers wanted to underline and then create an online survey for addressing quantitatively the subject. The directions of questions that were composed and used during the interview phase are stated below:

1. Which is the most important criterion when purchasing sunglasses?

2. In what time of the day do you wear your sunglasses most?

3. What do you like most about the sunglasses you own?

4. What do you dislike most about the sunglasses you own?

5. What would you improve in your sunglasses?

6. What is the most important criterion when purchasing watches?

7. In what time of the day do you wear most a hand watch?

8. What do you like most about your hand watch?

9. What do you dislike most about your hand watch?

10. What would you improve in your hand watch?

\section{Customer Needs}

Customers express their needs through statements. These raw data can be translated and expressed under a specific number of needs. In other words, customer needs were generated after the analysis of the data that have been gathered from the interviews and the observation of customers during their daily routine. Table 1 contains the needs that emerged regarding the sunglasses and the hand watch respectively. The relative importance of the needs was conducted through an online survey that was consisted of 312 responses. Participants were allowed to place at the same rank more than one need. 


\section{Table 1}

Customer needs per product

\begin{tabular}{l|l}
\hline Sunglasses needs & Hand watch needs \\
\hline Aesthetics & Price \\
\hline Sun Protection & Functionality \\
\hline Price & Comfort \\
\hline Durability & Aesthetics \\
\hline Eco Friendly & Technology \\
\hline Comfort & Robustness \\
\hline
\end{tabular}

For example, if a participant deemed that both price and durability are the most important needs to him/ her, then he/she could place both of them at rank 1, leaving rank 5 unallocated. Regarding the sunglasses, the relative question that is referring directly to the importance of the needs is: Please rank the most important characteristics that you look for when purchasing sunglasses; 1 being the most important and 5 being the least important. According to the answers of the question above, almost $30 \%$ of the customers put aesthetics in the first place. Moreover, sun protection was also high rated, price and durability were placed somewhere in the middle. On the other hand, eco-friendly design was voted as less important criterion. Figure 2 depicts the hierarchy of the customer's needs that relate to the sunglasses. As can be seen by the diagram, aesthetics is always a high priority to consumers because the external appearance of the product is primarily responsible for the first impression (Avramović et al., 2013).

Similarly, the most relevant question concerning the importance of the needs for the hand watch is: Please rank the most important characteristics that you look

\section{Sunglasses}

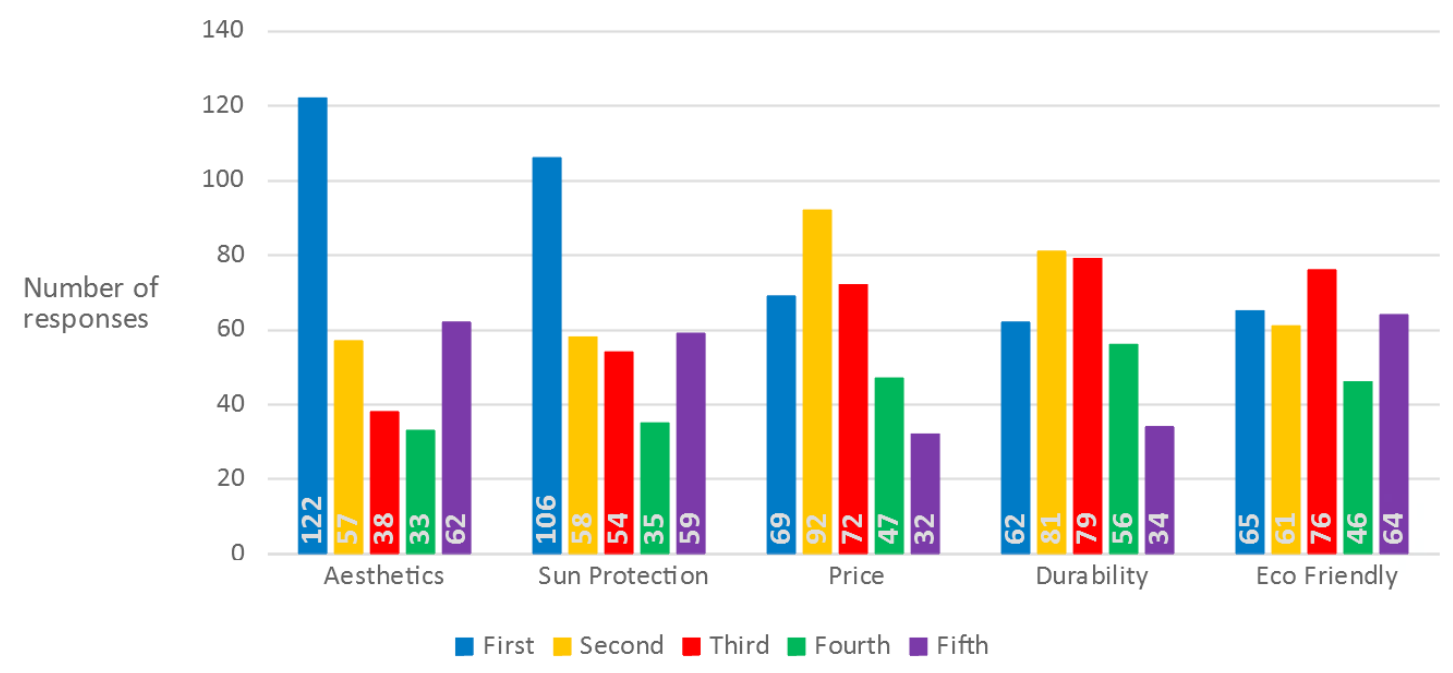

» Figure 2: Hierarchy of the needs for the sunglasses

\section{Hand Watches}

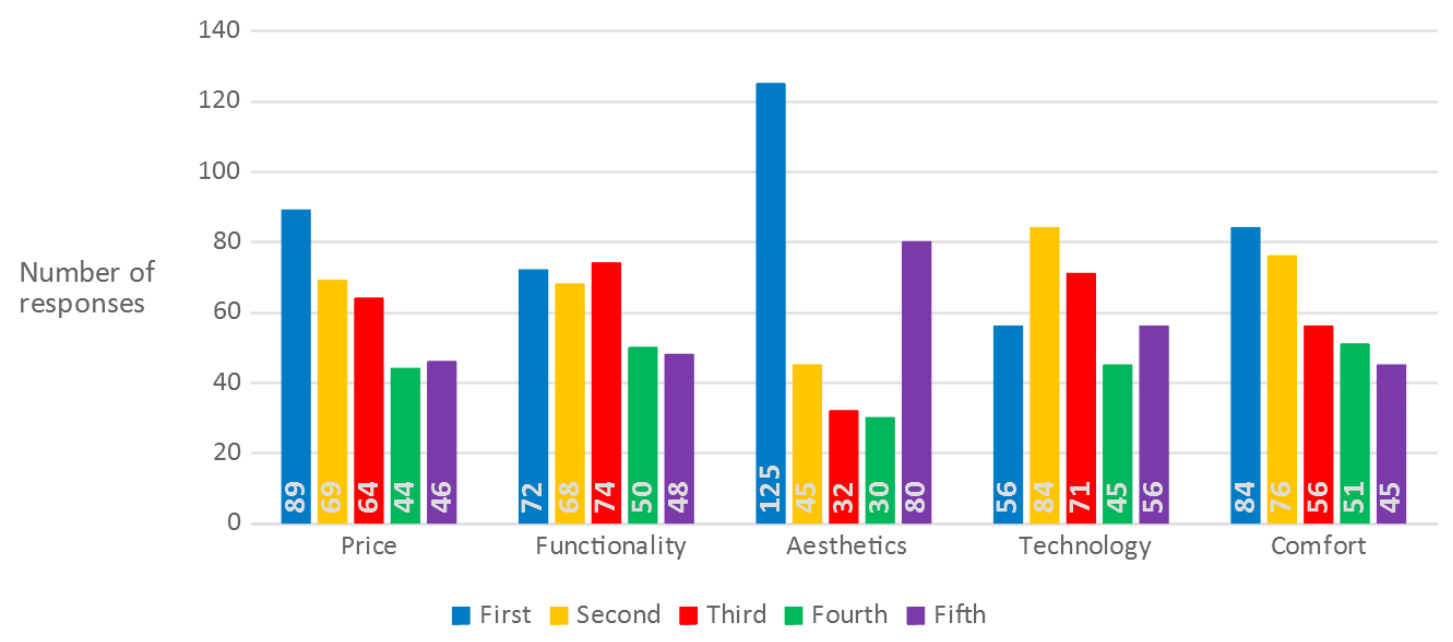

» Figure 3: Hierarchy of the needs for the hand watch 
for when purchasing watches; 1 being the most important and 5 being the least important. From Figure 3 it is obvious that aesthetics and price are on top of the customer's preferences, followed by comfort, functionality and technology. Technology was placed, with no significant difference at the bottom of the list.

\section{Brainstorming}

Several techniques were used for keeping track and organizing thoughts. These tools can be considered as part of the "process sketches", that is described right after, as long as they play fundamental role in the understanding of the design problem. During this study, mind maps were used in order to investigate the technical and morphological characteristics of the products (Da Luz et al., 2011). To be more specific, the glasses are analyzed in several categories i.e. materials, lenses, features, sizes, types and parts. These categories are organized furthermore in order to achieve a deeper understanding of the glasses' structure. In particular, the material section is divided in lens (glass, plastic, polycarbonate, SR-9) and frame materials (molded plastic, acetate, metal, animal products, wood). In addition, the lens feature category, is analyzed in coating (photochromic, gradient, mirrored, polarized), colors (gray, yellow/orange, brown/amber, green, purple/red, blue, polarized) and the different types of tint (clear, light, medium, dark, very dark). Furthermore, the size category relates to the Lens', the bridge's and the temple's Length. Moreover, all the different styles of glasses (Aviator, Cubmaster, Wayfarer, Rimless, Lens shape oriented, hobby oriented and the transformable glasses) are positioned in types category and last but not least the glasses parts (Lenses, Eye Wires/ Rims, Bridge, Nose pads, Pads Arms, End Pieces, Temples, Temple Tips in Parts category). Figure 4 illustrates the basic concepts of the mind map for the sunglasses.

As for the hand watch, there have been a combination between the main components and some technological improvements, relating to the smart watch technology as well as other specifications and connection options. Specifically, the parts category is divided by the strap (leather, nato, pilot/aviator, rally, bracelet, zulu), the case body (crown, dial, hands, lug, crystal) and the buckle (modern and classic).The types of glasses are classified in four

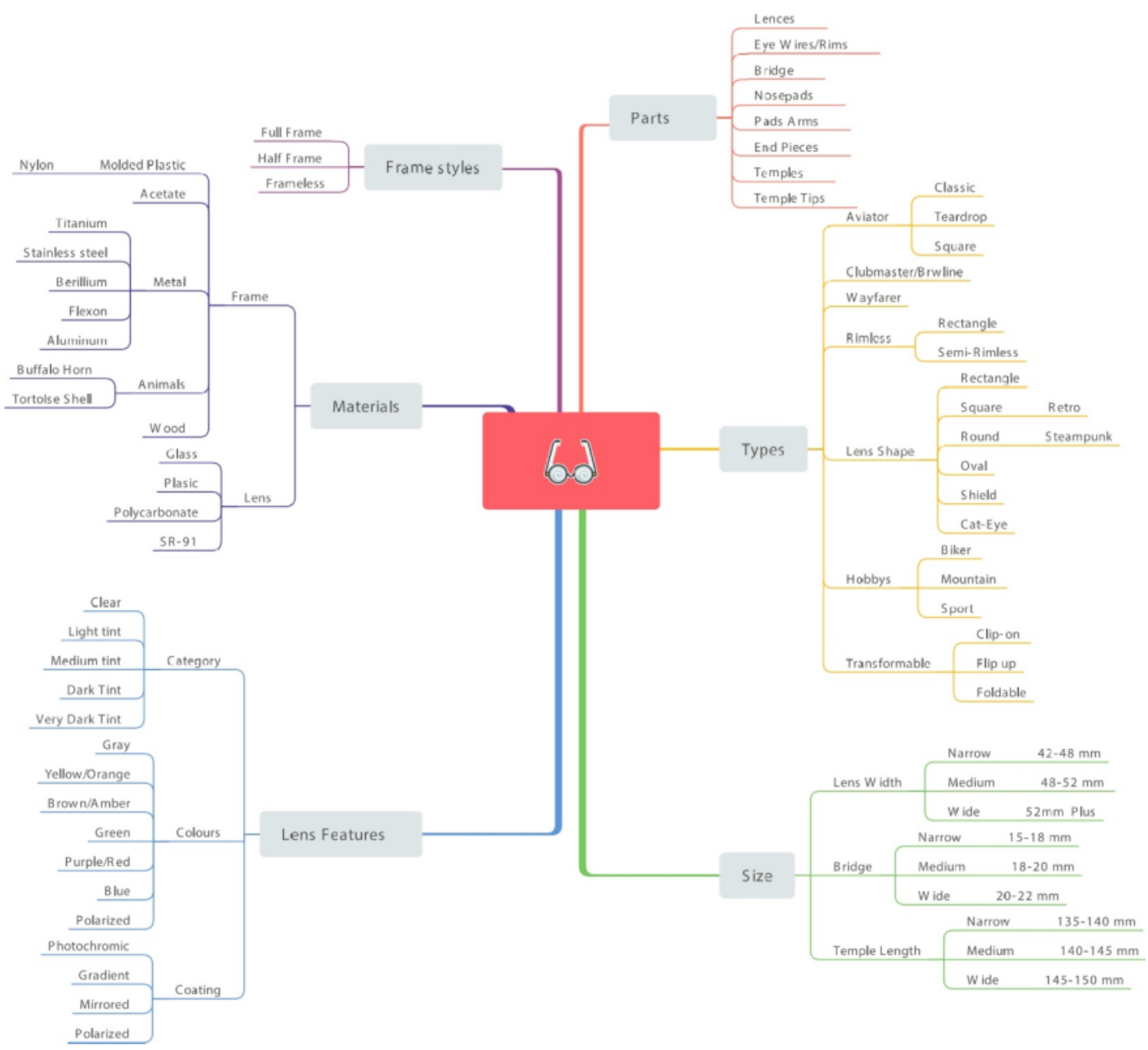

» Figure 4: Sunglasses basic concept directions for the mind map 


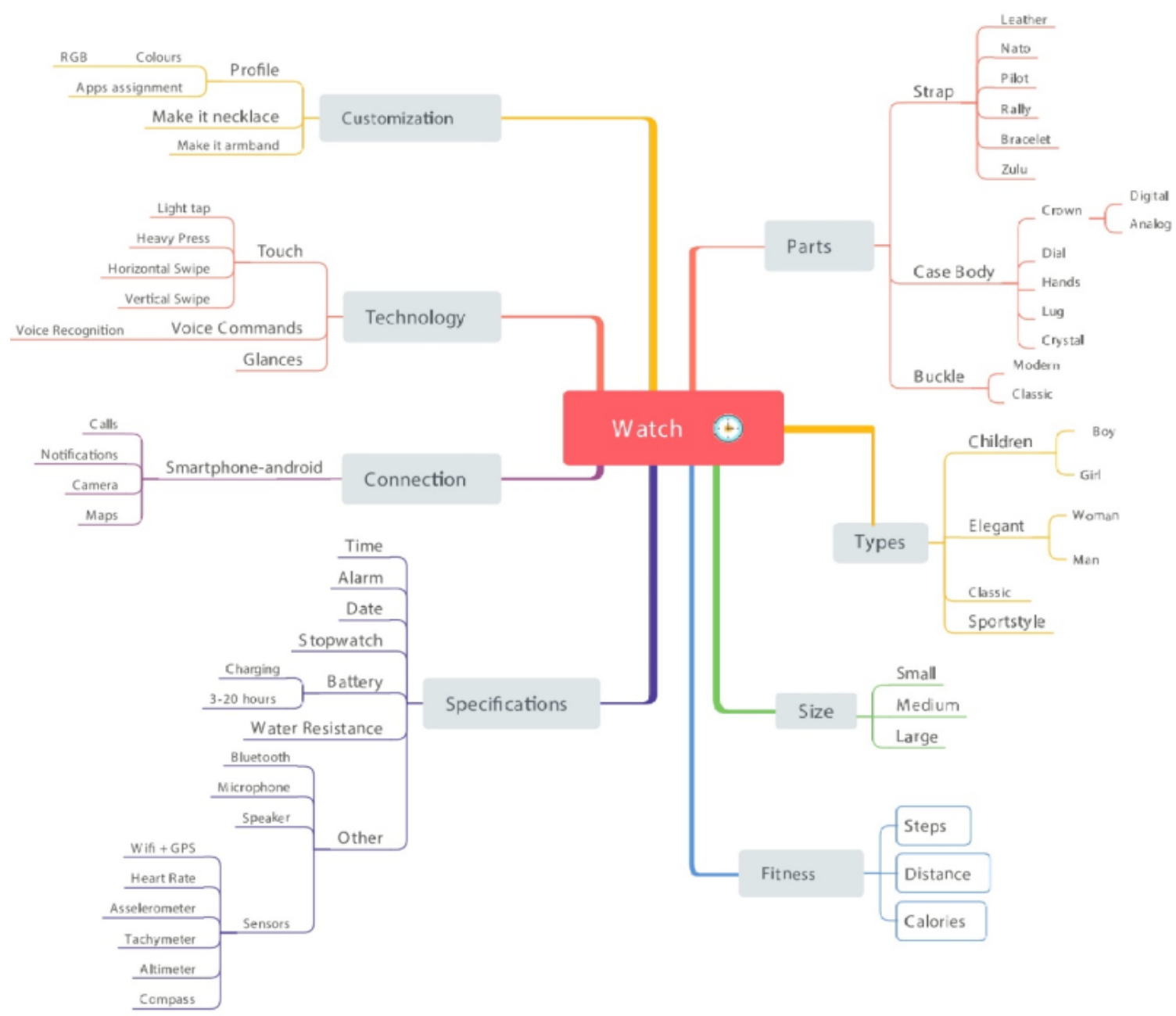

» Figure 5: Hand watch basic concept directions for the mind map

categories (children, elegant, classic and sport style) and the size in three (small, medium and large). Additionally, the "fitness" category, which is more sports oriented, is divided by steps, distance and calories. On top of that, classic hand watch specifications were mentioned like time, alarm, date, stopwatch, battery, water resistance and some other not so common (bluetooth, microphone, speaker and special sensors). As the smart watch technology advances, there has been further analysis concerning the connection (calls, notifications, camera, and maps) and other technology features (touch, voice commands, glances). At the end, a customization panel was added, in order to keep track of the design ideas. Figure 5 illustrates the basic concepts of the mind map for the hand watch. In addition, mood boards were used in order to illustrate ideas that cannot be expressed by words.

\section{Concept Generation}

Concept sketches are practical tools that help the designers to sharpen their sensory system. In most cases, freehand sketches are used to explore a number of ideas and experiment with different forms and geometries. This is an easy way to communicate design principles and aesthetic elements (Bruseberg \& McDonagh-Philp, 2001). In simple words, sketches give possible solutions to problems such as functions, ergonomics, aesthetics, colors, materials, methods of construction and so on. Conceptual design can vary from a simple line drawing that depicts an idea, to more complex drawings that define morphological characteristics, shading material indications and other elements of the final modeling.

The final stage is the CAD modeling design, which refers to a 3D computer aided representation of the final product.

As the design process advances, the designer has to choose carefully and selectively in order to separate the concepts that should be further processed from those that should be set aside. Therefore, they have been categorized in four groups with common characteristics: process sketches, ideation sketches, explanatory sketches and persuasive sketches (Rodgers, Green, \& McGown, 2000). 


\section{Expert Consultation}

The advice of an expert is always important as it provides clarity to question design process. In addition, it is possible to improve the optimization of the design process. For this reason, interviews with two optic stores were conducted in the city of Thessaloniki, Greece. The first one was recorded and the second one was written. These interviews were very critical to the design process and helped in the collection of valuable data.

The results regarding the preferences of the customers showed that their first priority is to purchase good looking sun glasses, while quality comes second. In addition, a common characteristic that customers are looking for is the absorbing/tinted lenses. This means that most of the time they look for good aesthetics and protection from the sun.

Regarding the rims' material, quality paste made of titanium or steel is the most durable choice. As for the lenses, brown, green and blue are the most preferable. Moreover, monochrome, gradient and polarized are high quality and popular.

From an economical perspective, customers are not willing to spend a lot of money in sunglasses purchase. Due to the recession there has been a downturn in sales, of about 30\% (Global No.1 Business Data Platform, 2018). According to sales directors, the most important characteristics in the design of sunglasses are the quality of the construction's materials and the durability of their structure.

\section{Product Concepts}

The candidates for the hand watch that served the purposes of this study were a solar charger watch, an armband watch, a voice command watch, a chronometer watch and a chronograph watch. Since the armband watch and the athletic sunglasses seem to be more attractive to a potential customer, the presented concepts in this research are limited to the "winners" of each category.

The armband watch (Figure 6) is referring to the customers that would like to own a stylish athletic watch and an armband that calculates calories, distance and heart rate, in one product. The whole idea is based on elastic strap extensions that are placed inside the main straps. The second ones connect with the case of the watch through magnets that hold them together. At the side of the case there are touch screen buttons. These are characterized by the attribute to identify the fingerprint of the user, in order to activate the armband mode. This touchscreen function also prevents the watch to unlock unwillingly. When they are pushed, the magnetic fields turn off and the straps extend. At that time, the user can lift the watch and adjust it to his or hers arm. Afterwards, when the straps are detached the screen rotates automatically. In this way, it switches from vertical to horizontal view and divides into two parts. The left side displays the time and the right one the counting of the distance, the calories and the heart rate. In addition, to the inner side of the straps there is a thin bracelet that stays connected with the watch also magnetically. Aside from the extra comfort it provides, this bracelet enables the detection of the heart rate. This means that when the watch turns into an "armband", all the magnetic fields turn off and the bracelet remains at the wrist of the user in order to keep track of the heart rate. Then, these data transfer to the watch via bluetooth and displayed on the screen. This happens, because the exact detection of the heart rate wouldn't be possible with the interference of the cloth.

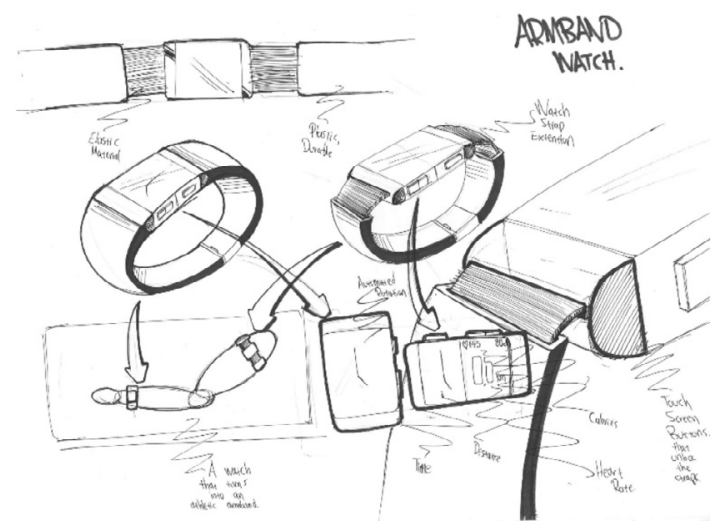

» Figure 6: Armband watch concept

Similarly, the candidates for the sunglasses product were the bamboo frame sunglasses, the adjustable tint sunglasses, the titanium frame sunglasses and the foldable frame sunglasses.

The frame of this particular pair of sunglasses is folded three times (Figure 7). It folds in the middle above the nose pads and at the two sides of the frame. In this way it becomes practical and convenient to carry. Also, the flat construction of the frame makes them ultra-robust and durable as well as the hypoallergenic nose pads provide extra comfort to the user.

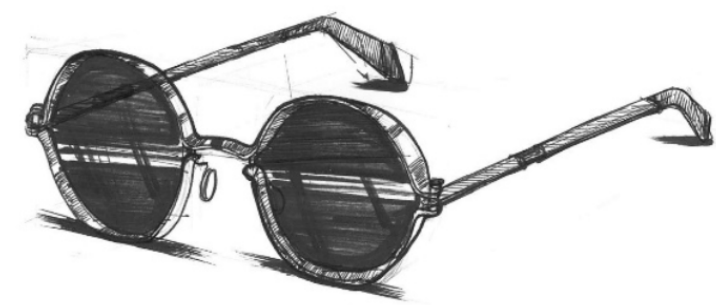

» Figure 7: Foldable frame sunglasses concept 


\section{Concept Screening}

Concept screening is a method of analyzing, improving and comparing concepts. This is a process of multi-voting the selected concepts taking into consideration the selection criteria that have been selected based on the customer needs research, from raw data collection, questionnaire and consulting experts.

The concept screening works simply by comparing the candidate products against a benchmark base option. The scoring $+1,0$ and -1 are usually used in order to state if the candidate option is better, same or worse compared to the benchmark option. In the concept screening method, a concept is chosen, that is more familiar to the designer, as a reference and all the other concepts are compared with it. Thus, in this study only the important criteria were included of equal weight and a great number of unimportant criteria were skipped as they may lead to false results.

Table 2 shows the criteria used in the concept screening for the sunglasses, whereas Table 3 shows the criteria used for the screening process of the hand watch.

Table 2

Sunglasses concept screening

\begin{tabular}{l|c|c|c|c}
\hline $\begin{array}{l}\text { Selection } \\
\text { criteria }\end{array}$ & Bamboo & Tint & Titanium & Foldable \\
\hline Aesthetics & + & - & 0 & + \\
\hline Sun Protection & 0 & + & 0 & + \\
\hline Price & + & - & 0 & 0 \\
\hline Durability & - & + & 0 & + \\
\hline Eco Friendly & + & 0 & 0 & 0 \\
\hline Functionality & - & + & 0 & + \\
\hline Comfort & - & + & 0 & - \\
\hline Sum +'s & 3 & 4 & 0 & 4 \\
\hline Sum O's & 1 & 1 & 7 & 2 \\
\hline Sum-'s & 3 & 2 & 0 & 1 \\
\hline Net score & 0 & 2 & 0 & 3 \\
\hline Rank & 4 & 2 & 3 & 1 \\
\hline Continue? & No & Develop & No & Develop \\
\hline
\end{tabular}

With the conclusion of the screening process, the results came up with four "winners" two for each product category. A pair of athletic sunglasses with modern and sporty looks (Figure 8a) along with an athletic combination of hand watch and armband that fulfil most of the modern athlete's needs (Figure 8b).

The second option is a pair of foldable sunglasses with a more classy touch (Figure 9a) along with a classy hand watch with leather strap (Figure 9b) which leans towards the business and casual class alike.

\section{Packaging and Branding}

The art of packaging design lies between industrial and graphic design. In order to be successful, the packaging must be appealing to the customer. It ought to make intense the feeling of possession, to satisfy the vision and persuade the mind.

Packaging is extremely associated with marketing and distribution. All the types and forms of products need to be contained in a suitable package that will grant quantity and volume. However, at this point lies the question, does this take into account the customer needs? What defines the amount of thirst or hunger of the consumer? For this reason, packaging defines the lifestyle of the consumer and a good packaging designer should design the packages in order to accompany the products through the whole stage of their life cycle.

As centuries pass, consumers became more educated. They look for sustainable, functional eco-friendly products, that worth their price. For this reason, the packaging has to inspire honesty, trust and respect. Besides, it ought to tell a well-established story. The feelings that will emerge from customers do not really matter if it is for example humorous, dramatic or nostalgic.

Table 3

Hand watch concept screening

\begin{tabular}{|c|c|c|c|c|c|}
\hline Selection criteria & Solar charging & Armband & Voice commands & Chronometer & Chronograph \\
\hline Price & 0 & - & - & - & - \\
\hline Functionality & 0 & + & + & 0 & + \\
\hline Aesthetics & 0 & + & + & 0 & + \\
\hline Technology & 0 & + & + & + & - \\
\hline Robustness & 0 & - & - & 0 & + \\
\hline Comfort & 0 & 0 & 0 & 0 & - \\
\hline Sum +'s & 0 & 3 & 3 & 1 & 3 \\
\hline Sum O's & 6 & 1 & 1 & 4 & 0 \\
\hline Sum-'s & 0 & 2 & 2 & 1 & 3 \\
\hline Net score & 0 & 1 & 1 & 0 & 0 \\
\hline Rank & 0 & 1 & 2 & 3 & 4 \\
\hline Continue? & No & Develop & Develop & No & No \\
\hline
\end{tabular}




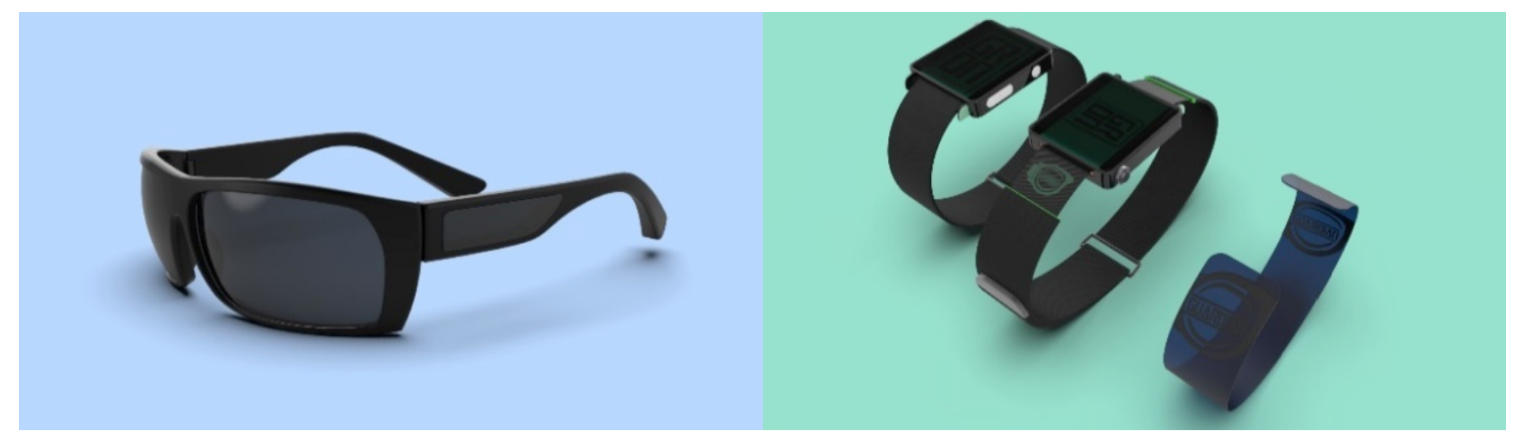

» Figure 8: Athletic sunglasses 3D model (a) - Athletic hand watch and armband 3D model (b)
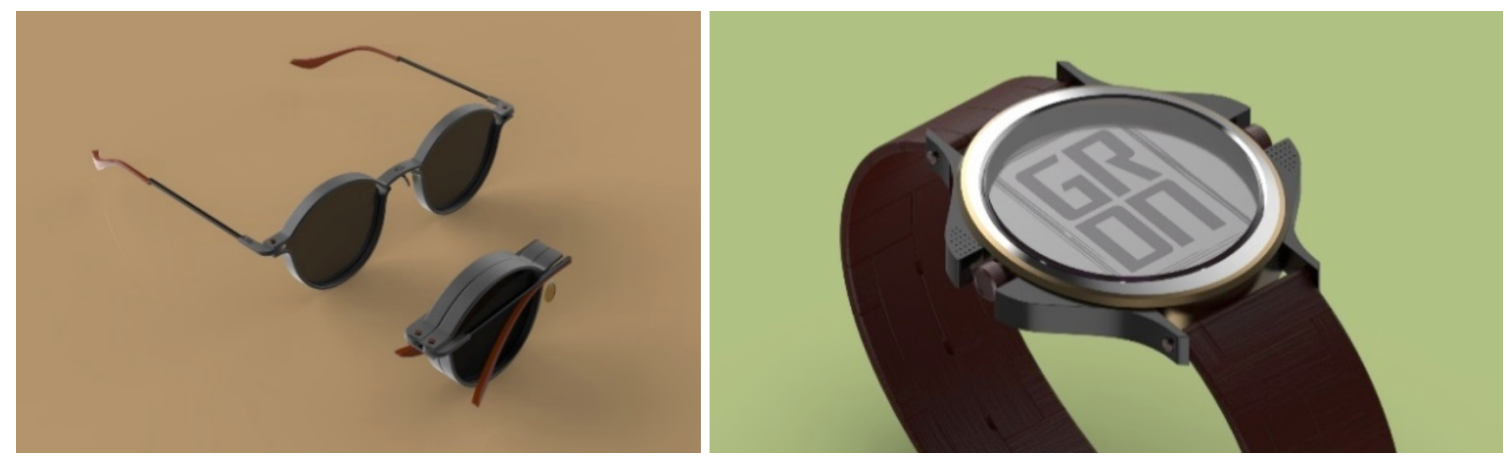

» Figure 9: Classy foldable sunglasses 3D model (a) - Classy hand watch 3D model (b)

\section{Logo Design: Guardian - Always watching you}

The idea of the name of this brand (Figure 10) came from the distinctive sunglasses' attribute, to protect the human eye from the sun radiation. Such strategies are common when designing a strong company logo (Adîr, G., Adîr, V. \& Pascu, 2012). Also, some properties of the designed watches that provide the user with information about the hour, the destination, the heart rates etc. are related to the safekeeping of a human. In addition, the interaction between the voice commands and the user strengthens this idea, by providing a feeling of secure and trust. Moreover, the motto "always watching you" is a word-play between the names of the two categories of the designed products. Specifically, the verb watch is related with the sunglasses, because they help the user to watch better. Furthermore, watching is a distinctive attribute of the guardian. The combination of the two designed products is also presented in the logo. In fact, three logos were designed that share the same aesthetic principles like minimalism, color and purposeful design.
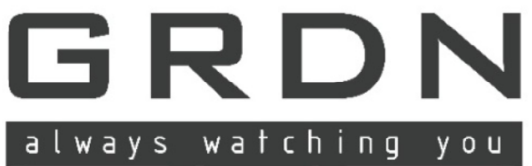

» Figure 10: Brand logo

\section{Packaging for athletic line of products}

This packaging was designed in order to be athletic, functional and dynamic. It consists of two components that they are connected with four magnets, which are located at the four corners of each piece. The purpose of this function is to give the user the option to carry the products either together or separated. In addition, another reason behind this design is to make easier the sale and the purchase of those two products together, as a set of inseparable items. The materials used are glossy plastic and plexiglass. The reason for using glossy plastic is that it gives the case an attractive shiny look and the reason for using plexiglass is that it partially exposes the product; according to Sabo et al. (2017) consumers tend to ignore a product that comes in a non-transparent packaging. Figure 11 illustrates the packaging for the athletic line of products which has a transparent window in the middle that fulfills the role of a display.

\section{Packaging for classic line of products}

Same concept with the previous packaging, this one was designed in a way so that the two products could be sold together as a set. In contradiction with the athletic products, these are more elegant and classier. Thus, the materials that this packaging is made of are wood, metal and gradient glass. In this way, it looks more luxurious and more appropriate for the category of products that is referring to. In order to open this 


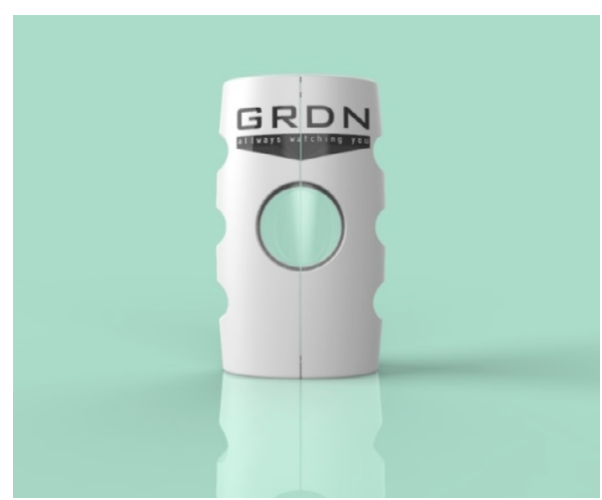

» Figure 11: Athletic lineup packaging

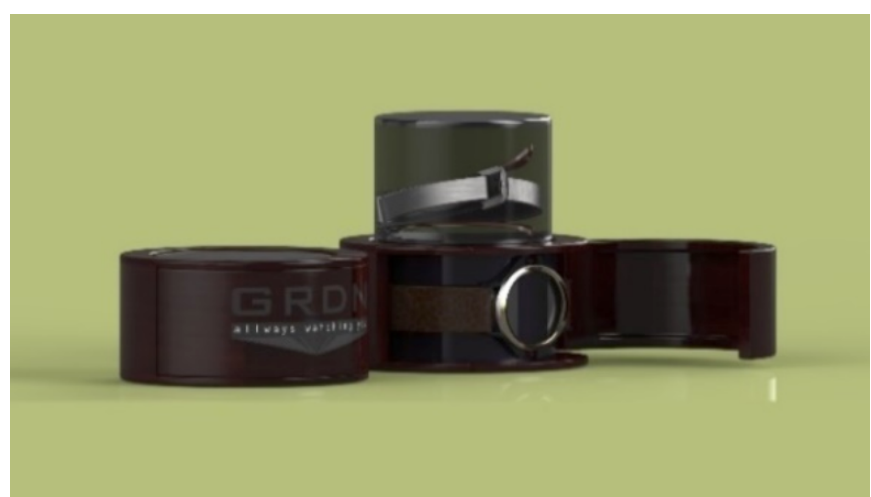

» Figure 12: Classic lineup packaging packaging, the user has to turn the wooden part, until it reaches the unlock point. Then the case opens and the watch is revealed. At that point, the second case that is placed inside the wooden part can be lifted and divided. This feature enables the package to be separated, which means that the user isn't obliged to carry the whole product when they do not want to. Figure 12 illustrates the packaging for the classic line of products.

\section{Conclusions}

During this study two sets of products and their packaging were developed and designed; one athletic pair of hand watch and sunglasses and a casual one. In order to reach the presented design, an external research was conducted in marketing, branding, packaging and product development. At first, raw data from target customers were gathered that then turned into customers' needs. Secondly, the hierarchy of those needs was performed based on the results of the online questionnaire about the sunglasses and hand watches design. Later on, these needs were translated into product specifications in order to start the concept generation phase. This phase begun with the clarification of the design problem and continued with the concept generation through the help of mind maps, mood boards and sketches. The packaging and branding phase started with the analysis of those two terms and the investigation of each other's relations. Finally, present study concluded with the generation of the brand, the relevant logos and the final CAD models of packaging.

\section{References}

Adîr, G., Adîr, V. \& Pascu, N. E. (2012) Logo design and the corporate identity. Procedia-Social and Behavioral Sciences. 51, 650-654. doi: 10.1016/j.sbspro.2012.08.218
Alexandridis, G., Symeonidou, I., Tzetzis, D., Kakoulis, K. \& Kyratsis, P., (2016) An integrated workflow of biomimetic design, material selection and computer aided engineering. Academic Journal of Manufacturing Engineering. 14 (4), 12-18.

Ambrose, G. \& Harris, P. (2011) Packaging the Brand: The Relationship Between Packaging Design and Brand Identity (Required Reading Range). Lausanne, AVA Publishing SA.

Avramović, D., Vladić, G., Kašiković, N. \& Pinćjer, I. (2013) Aplicability of golden ratio rule in modern product design. Journal of Graphic Engineering and Design. 4 (1), 29-35.

Bruce, M. \& Daly, L. (2007) Design and marketing connections: creating added value. Journal of marketing management, 23 (9-10), 929-953. doi: 10.1362/026725707X250403

Bruseberg, A. \& McDonagh-Philp, D. (2001) New product development by eliciting user experience and aspirations. International Journal of Human-Computer Studies. 55 (4), 435-452. doi: 10.1006/ijhc.2001.0479

Crilly, N., Moultrie, J. \& Clarkson, P. J. (2004) Seeing things: consumer response to the visual domain in product design. Design studies. 25 (6), 547-577. doi: 10.1016/j.destud.2004.03.001

Da Luz, T., Loup-Escande, E., Christofol, H. \& Richir, S. (2011) The Collaborative Product Design and Help to Decision Making: Interactive Mind-Mapping. In: Bernard, A. (ed.) Global Product Development, Proceedings of the 20th CIRP Design Conference, 19-21 April 2010, Nantes, France. Berlin, Springer. pp. 237-244.

DuPuis, S. \& Silva, J. (2008) Package Design Workbook: The Art and Science of Successful Packaging. Rockport MA, Rockport Publisher.

Ghodeswar, B. M. (2008) Building brand identity in competitive markets: a conceptual model. Journal of product \& brand management. 17 (1), 4-12. doi: 10.1108/10610420810856468

Global No.1 Business Data Platform. (2018) Revenue of the eyewear market worldwide by country in 2018 (in million U.S. dollars). Available from: https://www. statista.com/ [Accessed 10th December 2018]. 
Kohli, C. (1997) Branding consumer goods: insights from theory and practice. Journal of consumer marketing. 14 (3), 206-219. doi: 10.1108/07363769710166792

Kouveli, A., Tzetzis, D. \& Kyratsis, P. (2017) Packaging design in today's industries: the case of olive oil packaging design. Journal of Packaging Technology and Research. 1 (1), 13-23. doi: 10.1007/s41783-0170008-z

Kyratsis, P., Efkolidis, N., Manavis, A. \& Tsagaris, A. (2015) Design for Skin and Shape: An Innovative Design Approach. Applied Mechanics and Materials. 809-810 (2), 1311-1316. doi: 10.4028/www.scientific.net/ AMM.809-810.1311

Kyratsis, P., Efkolidis, N., Manavis, A. \& Peristeri, S. (2013) Design for Skin and Shape in the packaging industry. Academic Journal of Manufacturing Engineering. 11 (4), 56-61.

Kyratsis, P., Manavis, A., Garcia-Hernandez, C. \& Efkolidis, N. (2014) Creative Design for Skin and Shape using advanced CAD systems. Applied Mechanics and Materials. 657, 1021-1025. doi:10.4028/www.scientific. net/AMM.657.1021

Manavis, A., Sourris, T., Dimou, E., Efkolidis, N. \& Kyratsis, P. (2019) An Inspiration from Nature Design Methodology for In-Store Displays. Journal of Packaging Technology and Research. 1-8. doi: 10.1007/s41783019-00057-w

Mohebbi, B. (2014) The art of packaging: An investigation into the role of color in packaging, marketing, and branding. International Journal of Organizational Leadership. 3, 92-102. doi: 10.33844/ijol.2014.60248

Moutaftsi P. \& Kyratsis P. (2016) Visual brand identity of food products: a customer's perspective. Journal of Applied Packaging Research. 8 (3), 1-14. doi: 10.14448/japr.08.0015
Norman, D. A. (2013) The Design of Everyday Things. New York, Basic Books.

Robertson, K. (1989) Strategically desirable brand name characteristics. Journal of Consumer Marketing. 6 (4), 61-71. doi: 10.1108/EUM0000000002563

Rodgers, P. A., Green, G. \& McGown, A. (2000) Using concept sketches to track design progress. Design studies. 21 (5), 451-464. doi: 10.1016/S0142694X(00)00018-1

Sabo, B., Bečica, T., Keleš, N., Kovačević, D. \& Brozović, M. (2017) The impact of packaging transparency on product attractiveness. Journal of graphic engineering and design. 8 (2), 5-9. doi: 10.24867/JGED-2017-2-005

Sherr, L. \& Dent, A. H. (2015) Material Innovation: Packaging Design. New York, Thames \& Hudson Ltd.

Solomon, R. M. (2017) Consumer Behavior: Buying, Having, and Being (12th Edition). Edinburgh, Pearson Education.

Ulrich, K. T. \& Eppinger, S. D. (2012) Product Design and Development (5th Edition). New York, Mc Graw-Hill.

Van Kleef, E., Van Trijp, H. C. \& Luning, P. (2005) Consumer research in the early stages of new product development: a critical review of methods and techniques. Food quality and preference. 16 (3), 181-201. doi: 10.1016/j.foodqual.2004.05.012

Wang, E. (2013) The influence of visual packaging design on perceived food product quality, value, and brand preference. International Journal of Retail \& Distribution Management. 41 (10), 805-816. doi: 10.1108/ IJRDM-12-2012-0113

Wever, R., Van Onselen, L., Silvester, S. \& Boks, C. (2010) Influence of packaging design on littering and waste behaviour. Packaging Technology and Science. 23 (5), 239-252. doi: 10.1002/pts.892

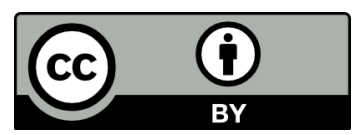

(C) 2019 Authors. Published by the University of Novi Sad, Faculty of Technical Sciences, Department of Graphic Engineering and Design. This article is an open access article distributed under the terms and conditions of the Creative Commons Attribution license 3.0 Serbia (http://creativecommons.org/licenses/by/3.0/rs/). 